ARH $-5 A-130$

Cont-720607--19

PLUTONIUM-URANIUM PARTITIONING

BY A REFLUX SOLVENT EXTRACTION

FLOWSHEET

L. E, BRUNS

MAY 4, 1972

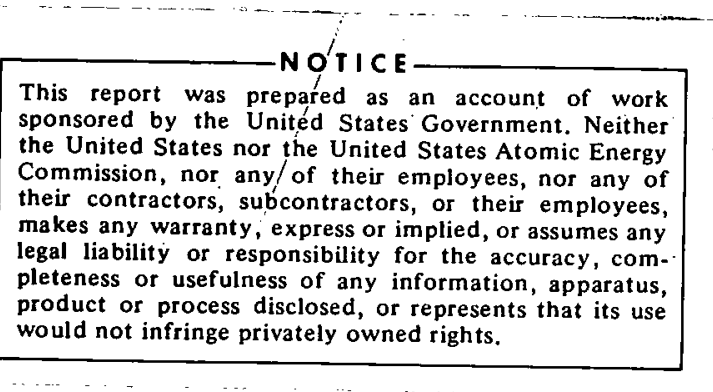

MSTRABUTDOA OF THLS DOCUREEAT IS UNLIMHTED 


\section{DISCLAIMER}

This report was prepared as an account of work sponsored by an agency of the United States Government. Neither the United States Government nor any agency Thereof, nor any of their employees, makes any warranty, express or implied, or assumes any legal liability or responsibility for the accuracy, completeness, or usefulness of any information, apparatus, product, or process disclosed, or represents that its use would not infringe privately owned rights. Reference herein to any specific commercial product, process, or service by trade name, trademark, manufacturer, or otherwise does not necessarily constitute or imply its endorsement, recommendation, or favoring by the United States Government or any agency thereof. The views and opinions of authors expressed herein do not necessarily state or reflect those of the United States Government or any agency thereof. 


\section{DISCLAIMER}

Portions of this document may be illegible in electronic image products. Images are produced from the best available original document. 


\title{
PLUTONIUM-URANIUM PARTITIONING
}

BY A RËFLUX SOLVENT EXTRACTION FLOWSHEET

\author{
By \\ L. E. Bruns \\ Plutonium Process Engineering \\ Operations Support Engineering Department \\ Chemical Processing Division
}

ATLANTIC RICHFIELD HANFORD COMPANY RICHLAND, WASHINGTON

For presentation at the

American Nuclear Society Annual Meeting

Las Vegas, Nevada

June $18-22,1972$ 


\section{TABLE OF CONTENTS}

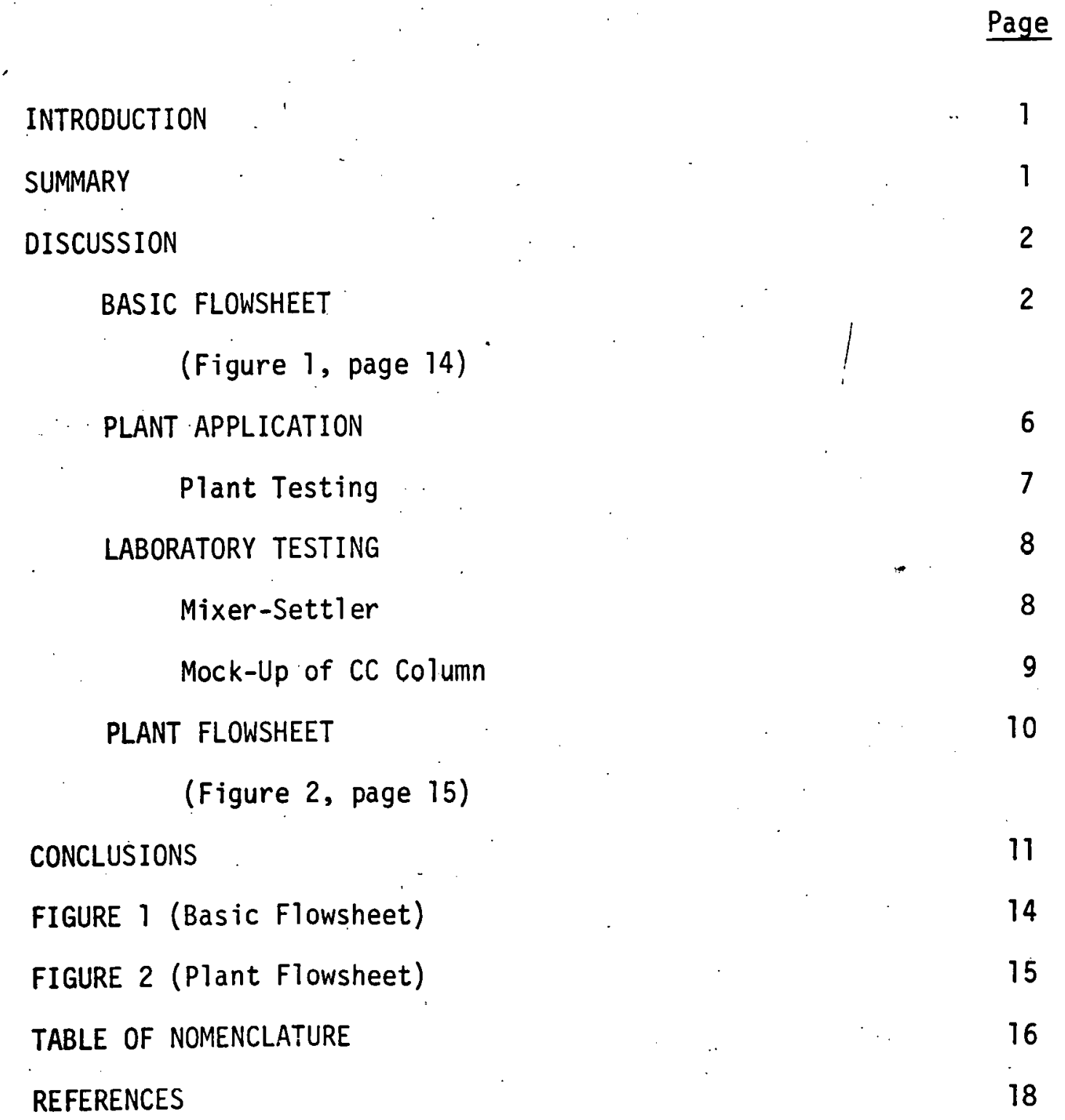




\section{ABSTRACT}

A new solvent extraction flowsheet has been developed for the processing of unirradiated plutonium-uranium scrap. By refluxing plutonium product as plutonium-III in a multistage plutonium stripping-partitioning system, uranium is salted into the organic and pure plutonium is quantitatively separated from uranium. A hydrofluoric acid strip removes the final traces of plutonium from the organic phase containing the uranium. The flowsheet was plant-tested; and problems evident in the plant test were solved by comprehensive laboratory tests. Plant flowsheets were successfully tried; further laboratory tests were made to enhance column control. 


\section{PLUTONIUM-URANIUM PARTITIONING \\ BY A REFLUX SOLVENT EXTRACTION FLOWSHEET}

\section{INTRODUCTION}

A new solvent extraction flowsheet has been devised for the separation and purification of plutonium from systems containing uranium. The flowsheet permits the purification and concentration of plutonium in a single solvent extraction cycle. This new concept was developed by Atlantic Richfield Hanford Company for use in the Plutonium Reclamation Facility, a plutonium scrap processing plant operated under prime contract for the Atomic Energy Commission.

It appears that this flowsheet could be applied directly to the processing of scrap from fuel fabrication for both the light water and fast breeder reactors. With further development, it might be usefur in the processing of irradiated fuels.

The development of the flowsheet, the parameters pertinent to process performance, and plant experience are described in this paper.

\section{SUMMARY}

After the plutonium-uranium scrap is dissolved or leached, the resulting solution is adjusted for salting strength and the plutonium is adjusted to the extractable (IV) and (VI) states. Uranium and plutonium are coextracted in a multistage extractor (unit I, figure 1), using 20 percent TBP (tributyl phosphate) in $\mathrm{CCl}_{4}$ (carbon tetrachloride) as the solvent. In the same extractor, the loaded solvent is scrubbed for impurity removal. 
In a second multistage unit (unit II, figure 1), plutonium is reduced to the aqueous favoring plutonium-III state with hydroxylamine nitrate. The purified plutonium-III leaving the concentrated end of this second multistage unit is split into a product stream and a reflux stream. The reflux stream flows to a holding tank where it is oxidized to the extractable plutonium-IV state by merely adding nitric acid. This plutonium-IV stream is re-introduced as a scrub stream in the first extractor. Plutonium-III product is withdrawn from the system when a 30 to 60 -gram plutonium/liter concentration is attained. Uranium is removed from the plutonium-III by a 20 percent TBP-CCl${ }_{4}$ scrub in the initial stages of this second extractor (see figure 1).

The uranium quantitatively leaves the second extractor via the organic stream. The plutonium impurity (about 1 percent) in this uranium stream is removed by a novel hydrofluoric strip in a third extractor (unit III, figure 1). Further conventional extractors (not discussed in this paper) remove the uranium and organic impurities from the organic stream.

The flowsheet has been tested in the laboratory and the plant to identify and correct process difficulties. Full-scale plant application has been made along with further development studies.

\section{DISCUSSION}

\section{BASIC FLOWSHEET}

Scrap bearing plutonium and uranium is dissolved or leached, and appropriate salting and plutonium valence adjusting agents are added as required. Both plutonium and uranium are quantitatively coextracted from the feed by a mixture of 20 percent TBP. in a $\mathrm{CCl}_{4}$ diluent. This extraction operation can be performed in some type of multistage equipment, e.g., a mixer-settler unit or a packed or pulsed column unit. The solvent extraction system is depicted in figure 1 . 
Addition of nitric acid and sometimes nitrite ion to the aqueous extraction unit feed ensures a predominance of plutonium-IV, with some plutonium-VI. This valence combination is extractable within ten mixer-settler stages (about $7-8$ theoretical stages). The uranium in the stable VI valence is easily extractable. Sufficient stages are used to ensure negligible plutonium and uranium losses in the salt waste.

Additional scrub stages are required for removing entrained and extracted impurities from the plutonium and uranium in the organic phase. Two scrub streams are used. The initial 2-stage scrub section uses refluxed plutonium product plus additional nitric acid as the scrub stream and removes the bulk of the impurities from the uranium and plutonium. One additional scrub stage uses a pure nitric acid scrub stream and removes the final impurities from the refluxed plutonium product with repeated washings. The number of stages required will depend upon the degree of impurity removal required.

The coextracted plutonium-uranium flows to a combination plutonium stripping and plutonium-uranium partitioning unit -unit II in figure 1. The organic stream enters unit II at the fourth stage, leaving three stages of scrub section for removal of the uranium from the plutonium stream. The number of scrub stages used depends upon the desired capacity. For the maximum-sized equipment allowable to provide criticality control (e.g., geometrically favorable 6-inch diameter sieve plate pulse column) and using a 20 percent TBP extractant, three stages of uranium scrub provide a potential of $100 \mathrm{~kg}$ per day uranium capacity. Organic of the same composition as used in unit I is" used as scrub in unit II and is introduced in stage 1 (see figure 1 ). 
Two stripping solutions are introduced into the stripping partitioning unit, unit II -- one at the 24-stage and one two stages below the organic feed stream entry point, the sixth stage. The stripping streams contain various amounts of reducing agents, hydroxylamine nitrate and nitric acid. An estimated 20 stages are required for quantitative stripping of the plutonium from the organic phase.

The two effluent streams from unit II are the pure plutonium product and the organic effluent, containing the uranium and a minor amount of the plutonium (usually less than 0.1 gram per liter). Almost all of the plutonium product is refluxed to the thirteenth stage of unit I as the intermediate scrub. When the refluxed plutonium stream reaches the desired concentration, plutonium is drawn off as product.

The partition principle is based on maintaining a high concentration ( 30 to 60 grams per liter) of predominantly plutonium-III in the scrub section and the initial stripping stages (stages 5 and 6). Plutonium-IV and plutonium-VI favor the organic in a salted medium, whereas plutonium-III favors the aqueous phase even in a salted medium. The high concentration of plutonium-III nitrate salts the uranium into the organic phase. The unit II scrub stream (20 percent TBP in $\mathrm{CCl}_{4}$ ) removes residual uranium quantitatively, and the plutonium is only slightly refluxed in this scrub section.

The high plutonium-III nitrate salting strength is maintained with a reducing agent. Selection of the reducing agent is the key to the 1-cycle system. The reducing agent must be strong enough to cause a predominance of plutonium-III in the scrub section and the concentrated product portion of the stripping section. The reducing agent must not introduce impurities, since much of it remains with the concentrated plutonium product. 
The reducing agent found to be optimum was hydroxylamine nitrate (HN). This chemical can reduce plutonium-IV to plutonium-III in low nitric acid mediums $(0.5-1.5 \mathrm{M})$. Other reaction products are gases -- $\mathrm{N}_{2} \mathrm{O}$ (major constituent), $\mathrm{N}_{2}$; and a smal1 amount of $\mathrm{NO}_{2}$. However, the equilibrium shifts quantitatively to plutonium-IV in nitric acid concentrations greater than 3.5M.

One problem with $\mathrm{HN}$ is the formation of small amounts of $\mathrm{NO}_{2}$ gas from the reaction of plutonium-IV with $\mathrm{HN}$. Some of the $\mathrm{NO}_{2}$ is solubilized and forms a nitrite ion which oxidizes plutonium-III to plutonium-IV. The $\mathrm{NO}_{2}$ reacts with $\mathrm{HN}$, forming $\mathrm{N}_{2} \mathrm{O}, \mathrm{N}_{2}$, and small amounts of additional $\mathrm{NO}_{2}$. If $\mathrm{NO}_{2}$ reactions form more $\mathrm{NO}_{2}$, the reaction can become autocatalytic and the HN can be destroyed, and plutonium-III tends to convert back to plutonium-IV. 'This conversion back to plutonium-IV can be minimized, as explained in the following paragraphs.

The stripping agent introduced at the dilute plutonium end of the stripping-partition unit, unit II (see figure I, stage 24), forms plutonium-III. As the aqueous or light phase goes from stage 24 to 23 , etc., an autocatalytic breakdown of $\mathrm{HN}$ begins to take place due to the formation of the nitrite ion. The excess $\mathrm{NO}_{2}$ oxidizes plutonium-III to plutonium-IV, and plutonium-IV may predominate in the middle stages $(13,14,15$, etc.). If plutonium-IV predominates, the flowsheet is not workable. (This will be discussed later under "Plant Testing.") If a second HN stream is added at about the sixth stage, a plutonium-III medium can be maintained between stages 6 and 1 ; and the formation of excessive plutonium-IV below the addition point is minimized. This second stream, 1.2M $\mathrm{HN}$ and $0.4 \mathrm{M} \mathrm{HNO}_{3}$, is added approximately two stages below the organic stream entry point.

One additional unit is important to the l-cycle system -- unit III. This unit is necessary due to the formation of DBP (dibutyl phosphate), the break down product of TBP (tributyl phosphate). DBP complexes plutonium as an almost unstrippable plutonium-IV compound, $\mathrm{Pu}\left(\mathrm{NO}_{3}\right)_{4} .2 \mathrm{DBP}$. HN will not efficiently strip plutonium from DBP. However, hydrofluoric 
acid will quantitatively strip plutonium from DBP. The stripping agent used is 2.5 $\mathrm{HNO}_{3}-0.25 \mathrm{M} \mathrm{HF}$. Nitric acid serves two purposes: (1) to ensure the bulk of the uranium stays in the organic phase (due to salting action of nitric acid), and (2) to prevent $\mathrm{PuF}_{4}$ precipitation. The solubility of $\mathrm{PuF}_{4}$ increases from 1 to 8 grams/liter as the nitric acid concentration is increased from 0.0 to $2.5 \mathrm{M}$.

With an estimated eight stages in unit III, the plutonium may be reduced to the 10 parts/million level. The organic stream is transferred to a simple water strip system where the uranium is removed for further processing in another facility. DBP is removed from the organic in another solvent extraction unit by use of a carbonate wash. The organic is reacidified and returned to unit I and unit II as an extractant and scrub respectively (see figure 1).

\section{PLANT APPLICATION}

The Atlantic Richfield Hanford Company's Plutonium Reclamation Facility was designed and built as a plutonium scrap (no uranium) recovery facility. (1) Plutonium-bearing scrap is dissolved or leached with a mixture of nitric and hydrofluoric acids. The resulting solutions are purified in a single-cycle solvent extraction system. The extraction column, called the CA column (see nomenclature for description of plant columns and streams, and figure 2 for flow sketch of the main Plutonium Reclamation Facility columns); and the plutonium stripping column, the CC column, are 4-inch diameter sieve plate pulsed columns. The CA column represents unit $I$ and the CC column represents unit II (see figure 1). A short packed column ( $C O$ column, unit III) is used for removing the final plutonium from the organic by an HF wash.

This cclumn system appeared adaptable to the basic flowsheet approach previously described, and plutonium-uranium scrap was available; hence, the decision was made to the test the plutonium-III reflux principle in the Plutonium Reclamation Facility. Plant stages 
available were not sufficient for high capacities (2 to 3 organic scrub stages, unit II; and 2 to 3 stages in HF strip column, unit III), but a significant capacity (10 kg uranium + plutonium per day) could be realized with only minor changes and additions. Later, additional stages could be added to increase plant capacity (up to $30 \mathrm{~kg}$ uranium + plutonium per day is deemed possible).

Initial separation flask laboratory studies showed that a single stripping solution (last stage, unit II) in the plutonium purificationpartition column should be adequate. To study the overall valence balance and kinetics, a plant test was needed.

\section{Plant Testing}

Several hundred pounds of plutonium-uranium scrap were processed through the Plutonium Reclamation Facility. However, the first attempt was not successful, since plant kinetics using a single stripping agent were such that a plutonium-IV medium predominated in the top and middle of the CC column. A brown plutonium-IV color was apparent where a blue color (characteristic of plutonium-III) should have been present. Although plutonium-IV has a smaller extraction coefficient than uranium, the law of mass action prevailed and the plutonium-IV took over the bulk of the immediate available organic sites in the organic scrub stream. The end result was plutonium refluxing down the column and uranium building up in the recycled plutonium product stream to as high as 10 percent.

Plutonium-IV and uranium accumulated in the center of the column, resulting in over-saturation of the organic and precipitation of the plutonium-IV nitrate DBP complex (only plutonium-IV can form this complex). Also, the high plutonium-IV accumulation resulted in high plutonium losses in the $\mathrm{CC}$ column organic effluent called the $\mathrm{CCW}$. The high amount of plutonium overloaded the final plutonium clean-up unit, the CO column. The HF strip precipitated $\mathrm{PuF}_{4}$, and high 
plutonium the uranium product resulted. Although the first plant test was unsuccessful, flowsheet problem areas were identified for subsequent comprehensive laboratory investigation.

\section{LABORATORY TESTING}

Laboratory testing was conducted in two different sets of equipment. One was a minimixer-settler unit to study the kinetics in certain areas; and the other, a mock-up of the plutonium stripping-partitioning column to study height of transfer units (HTU) and column gassing. Mixer-Settler

In this unit, plant solutions could be used, and the number of plant stages and residence times could be duplicated. The scale-down ratio was 500:1. All stages were visible, permitting color determination. The tests were set up to first duplicate plant problems, and then varied to solve those problems.

Plant problems were successfully duplicated. By using only a single CC column stripping agent at the last stage (bottom stage in the plant), a plutonium-III medium could not be attained, and the plutonium product soon contained excessive amounts of uranium.

Two flowsheet changes were made, and each produced excellent results. One was the addition of a second HN stripping stream added two stages below the organic inlet, as previously discussed. The other was use of hydrazine as a holding agent in the CC column bottom stripping stream. The hydrazine reacted with excess nitrite, and the mixer-settler system showed a blue plutonium-III color throughout. Although inexpensive, hydrazine has a flowsheet disadvantage. Nitric acid alone will not convert the plutonium-III returning to the CA column back to plutonium-IV if hydrazire is present. Nitrite must be added to destroy the hydrazine, and a "snowballing" effect can easily occur if excess nitrite is added. Serious gassing and 
reversals to predominant plutonium-IV mediums can result. Therefore, the more easily controlled hydroxylamine nitrate approach was selected.

The mixer-settler study concluded with a long demonstration run. (2) It demonstrated that the plant $C A, C C$, and $C O$ columns could probably handle $5 \mathrm{~kg}$ uranium/day (plus associated plutonium) with only the addition of a side HN stream.

Mock-Up of CC Column

The mock-up column duplicated the top 15 stages of the CC column. (3) Uranium was used, but plutonium could not be used in the pilot plant area available. To simulate the plutonium $\left(\mathrm{NO}_{3}\right)_{3}$ salting strength, sodium nitrate was added to the HN side stream. The same type of perforated stainless steel plates as those in the Plutonium Reclamation Facility plant CC column (unit II) were used. This was followed by a test with Raschig rings between the plates in the scrub section of the laboratory column (rings were also added to the Plutonium Reclamation Facility column).

The results showed

Gassing in the CC column actually improved column efficiency. To test severe gassing, excess nitrite was added to the system; however, no column flooding occurred. Gassing should be minimized in the plant to avoid organic entrainment into the plutonium recycle stream and eventual cavitation of pump in the product recycle hold-up tank.

- Height of a transfer unit (HTU) is lowered only slightly by the addition of 3/4-inch plastic Raschig rings between the plates in the scrub section of the column. The rings were added to increase mixing in the lower volume velocity scrub section 
- Height of a transfer unit studies showed that with optimization of column amplitude and frequency, at least four transfer units could be realized in the plant scrub section.

\section{PLANT FLOWSHEET}

The final plant flowsheet for processing unirradiated plutoniumuranium scrap in the Plutonium Reclamation Facility is depicted in the flow sketch shown in figure 2 . The abbreviations used in figure 2 , plus other abbreviations and symbols used throughout the article are explained in the "Table of Nomenclature," page 16. Existing equipment was used, so there are some capacity limitations. For example, the CC column originally designed as a plutonium stripping column was divided into a stripping-scrub column. Hence, some stripping area was lost, and not as many scrub stages as desired could be added. The Co column is a simple packed column with only two to three stages (eight shown in figure 1) available. Also, the small uranium strip column was capable of handling only $5 \mathrm{~kg}$ uranium/day.

A color code is also used, showing the valence balance throughout a column system. The dark brown to black color shows a high concentration of plutonium-IV (some green plutonium-VI is present, but it is dwarfed by the predominant plutonium-IV). Plutonium-III in the aqueous phase (the light phase) is blue. The organic, when free of actinides, is a yellowish color.

The CA column is an organic continuous unit with the aqueous being the dispersed phase. Here, the interface is at the top. In the $C C$ and Co columns, the anqueous phase is continuous and the interface is at the bottom (I stands for interiace, figure 2).

The new flowsheet was tested in the plant, and greater than $5 \mathrm{~kg}$ uranium/day were realized. The plutonium product easily met uranium specifications and, with experience, satisfactory CC column control was established. A new uranium strip column was recently installed, 
scrub stages were added to the $\mathrm{CC}$, column, and other improvements were made, the goal being a combined uranium-plutonium capacity of $30 \mathrm{~kg}$ per day. The new system will be tried in the fall of 1972 .

Added laboratory development work demonstrated that the addition of $\mathrm{HN}$ at three points in the CC column would give easier column control and would require less $\mathrm{HN}$ overal1. Other laboratory tests were made on the solubility of $\mathrm{N}_{2} \mathrm{O}$ in $\mathrm{CCl}_{4}$, ways to avoid plutonium-IV take-over, methods of re-establishing a plutonium-III system if plutonium-IV begins to take over, and CO column studies. Tests are in progress on the hydrazine-HN flowsheet, automatic column controls, and organic clean-up systems. The plant feasibility has been established and, with further plant experience and laboratory assistance, a routine flowsheet should result.

\section{CONCLUSIONS}

A new plutonium-uranium scrap processing flowsheet (see figure 2) has been developed from theoretical considerations, laboratory testing, and plant testing. Important conclusions based on this work include the following:

1. A plutonium stripping or combination plutonium-uranium partition - plutonium stripping multistage solvent extraction system (as discussed above), operating on the reflux flowsheet principle, can operate on a plutonium-III system. Use of the reducing agent hydroxylamine nitrate and minimal use of nitrite in the extraction feed can give an easily controlled plutonium-III system. The plutonium-III system not only has the advantage of an excellent plutonium profile (variation of plutonium concentration with stages), but it avoids plutonium polymer precipitation (possible in lowacid mediums like the $\mathrm{CC}$ unit) and $\mathrm{Pu}\left(\mathrm{NO}_{3}\right)_{4}: 2 \mathrm{DBP}$ precipitation in the middle of the stripping unit. 
2. A flowsheet for plutonium-uranium scrap processing has been developed that can avoid additional plutonium and uranium cycles. The extra plutonium cycles can be avoided by the reflux flowsheet principle, which gives a concentrated pure plutonium product. Many solvent extraction systems are oncethrough systems (i.e., no refluxing) with several plutonium and uranium cycles. Such systems demand higher nitric acid concentrations for partitioning; hence, an impurity-laden (iron) reducing agent like ferrous sulfamate is required. In once-through systems, the plutonium product from the partitioning unit will frequently be low in plutonium (especially in a plutonium-uranium scrap processing facility with its variable plutonium content in the scrap), and metallic impurities will be excessive. At least one more complete cycle is required -- and probably two -- to attain required purity level if the once-through principle is maintained in the additional cycles.

Further uranium cycles may be avoided by keeping the DBP build-up at a minimum and by use of the HF strip unit. The Plutonium Reclamation Facility uses an existing column, and the facility layout was such that column dimensions could not be economically altered to meet uranium specifications (10 parts plutonium/billion parts uranium). A new facility may be able to avoid this problem. Studies are in progress to try to attain these rigid specifications without further uranium cycles.

3. Geometrically-favorable equipment is required with the reflux flowsheet system. However, geometrically-favorable systems are usually selected for final plutonium purification with any flowsheet. Geometrically favorable means nuclear safe by geometry (usually minimum diameter, annulus, or slab thickness) for the worst foreseeable abnormal occurrence in the facility. 
4. An adaptation of the proposed flowsheet might be useful in power reactor fuel reprocessing, especially where breeder reactors are concerned (high plutonium concentrations, e.g., 20 percent plutonium). A new facility could conceivably process $500 \mathrm{~kg}$ uranium/day plus plutonium if 1 imited to a cylindrical geometrically-favorable facility.

5. Plutonium can be removed from the organic degradation product DBP with dilute hydrofluoric acid - nitric acid mixtures. Other reducing agents (1ike ferrous sulfamate) are unsatisfactory for this purpose. 
FICURE

\section{REPRESENTATION OF THEORETICAL FLOWSHEET}

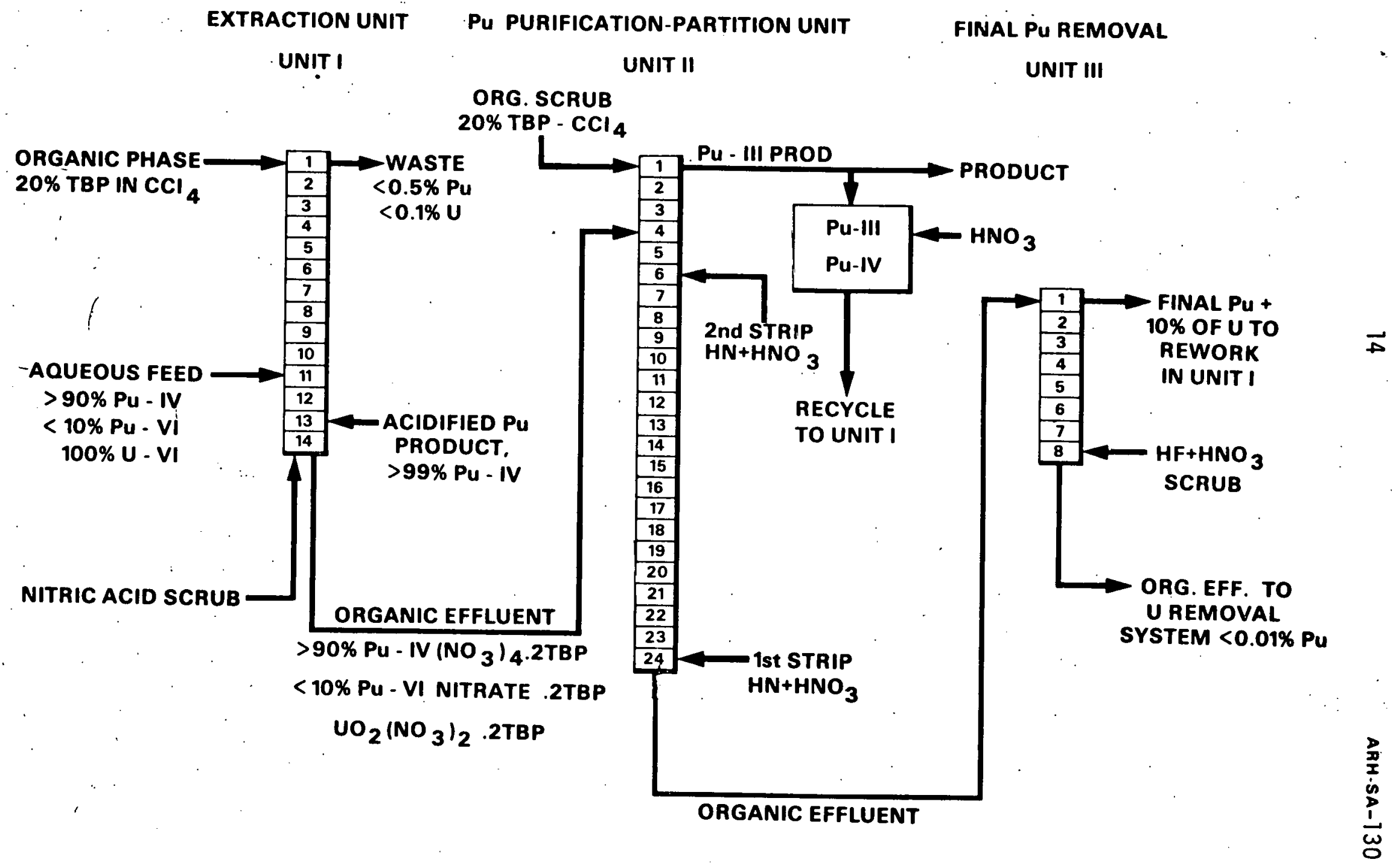


FIGURE ?

PLANT FLOWSHEET

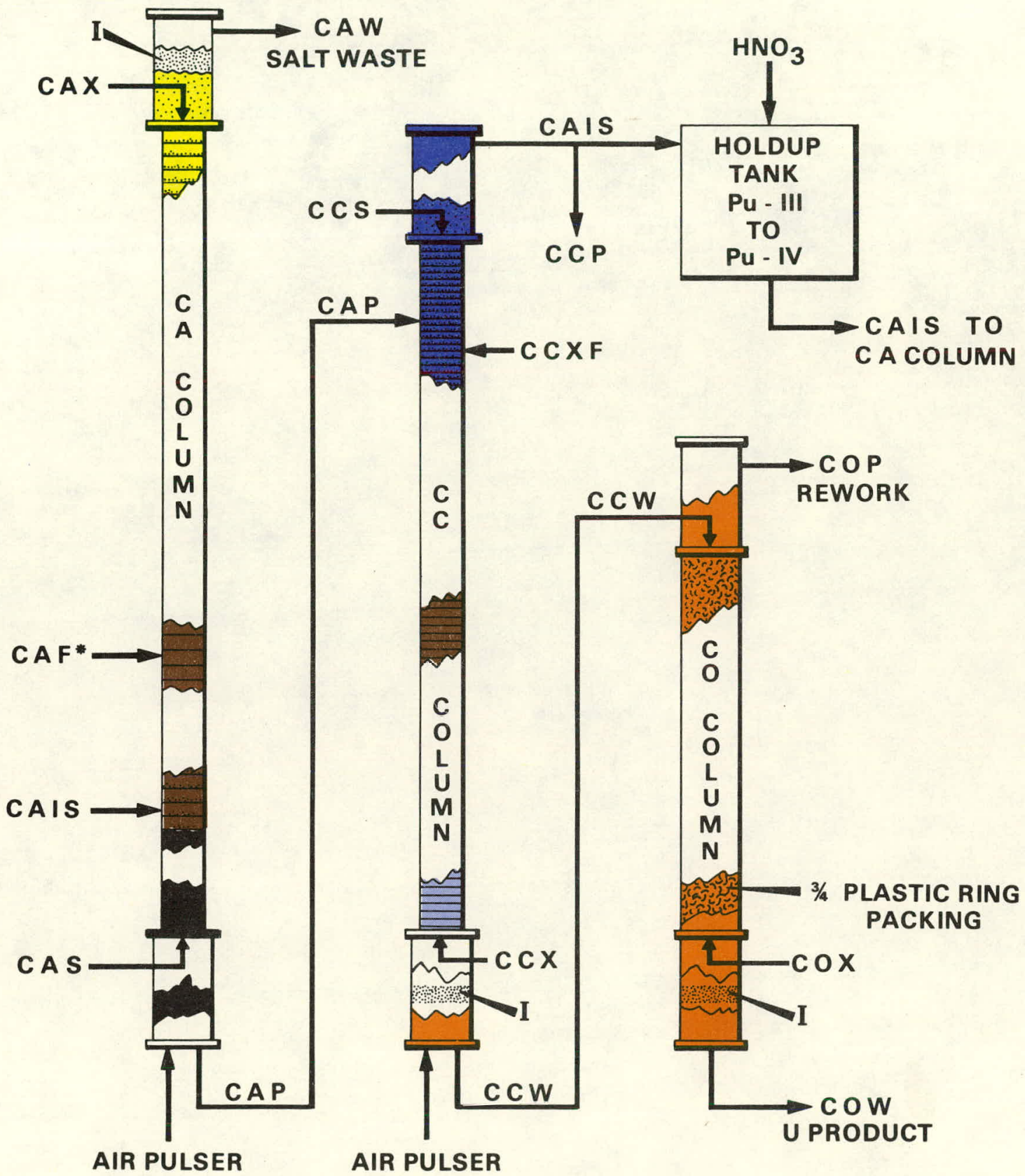

BROWN -Pu - IV (1-15 g/ $\mathrm{g}) \quad$ YELLOW - 20\% TBP IN $\mathrm{CCI}_{4}$ NEGLIBLE Pu BLACK - Pu - IV $(15-30 \mathrm{~g} / \ell)$ ORANGE-BROWN-U-VI $(1-20 \mathrm{~g} / \ell)$ BLUE - Pu - III $(5-60 \mathrm{~g} / \mathrm{\ell})$

- Refer to page 15 for description of eAch stream and Column 


\section{TABLE OF NOMENCLATURE}

Geometrically Faborable

Facility

TBP

$\mathrm{CCl}_{4}$

CA column

CAF

CAX

CAIS

CAS

CAP
A facility processing fissionable material which is safe from criticality by equipment design

Tributyl phosphate, the extractant used in this solvent extraction process

Carbon tetrachloride, the diluent used for the TBP

The Plutonium Reclamation Facility sieve plate, air-pulsed, continuous extraction column. This column co-extracts the plutonium and uranium and scrubs the impurities from the plutonium and uranium in the organic stream.

The aqueous feed to the CA column

The organic stream used in the CA column. It contains 20 percent of the TBP extractant in the $\mathrm{CCl}_{4}$ difuent. The organic phase is the continuous and the heavy phase.

The refluxed plutonium product stream. This stream gives extra volume velocity to the scrub section, improving the plutonium-uranium clean-up efficiency.

A nitric acid scrub at the bottom of the CA column. For most feeds, a $2 \mathrm{M} \mathrm{HNO}_{3}$ is used. With refluxing product (CAIS), the CAS is able to recontact the plutonium product for purification many times before the plutonium product is removed from the system.

The organic effluent from the CA column containing all the co-extracted plutorium and uranium. The plutonium concentration will normally be higher than the uranium, since plutonium is refluxed.

Interface between the two phases. The interface will either be in the bottom or top disengaging section, depending upon which is the continuous phase, e.g., organic phase -- I at top; aqueous phase -- I at bottom. 
CC column

$\operatorname{CCS}$

$\operatorname{ccx}$

CCXF

CCW

CCP

CO column

$\operatorname{cox}$

COW

4.

COP

$H N$

DBP

HF

Plutonium-III

-IV

$-V I$
The combination plutonium stripping - partitioning column. It is a sieve plate, air-pulsed column.

The organic scrub which removes the uranium from the plutonium product in the CC column

The initial CC column strip, 0.2 to $0.5 \mathrm{M} \mathrm{HN}$ and $0.15 \mathrm{M} \mathrm{HNO}_{3}$, added at the bottom of the column

The second CC column strip, 1.2M HN - 1.OM $\mathrm{HNO}_{3}$, added about two stages below the CAP entry point

The CC column organic effluent containing all the uranium and usually less than 0.1 gram/liter plutonium

The final purified plutonium product

The column for removing the final plutonium from the uranium-laden organic

The hydrofluoric acid strip for the CO column, $0.25 \mathrm{M} \mathrm{HF}-2.5 \mathrm{M} \mathrm{HNO}_{3}$

The Co column organic effluent. This stream goes to conventional uranium and organic handling equipment, i.e., a packed water strip column for removing nitric and uranium from the organic and a column for removing such degradation products as DBP from the organic by a carbonate strip.

The aqueous effluent from the co column which contains the remaining plutonium and 10 percent of the uranium entering the CO column via the CCW. The COP flows to the extraction feed system for rework.

Hydroxylamine nitrate

Dibutyl phosphate, a degradation product of TBP Hydrofluoric acid

The valence state of plutonium 


\section{REFERENCES}

1. L. E. Bruns, "Geometrically Favorable Plutonium Scrap Recovery Plant," Chemical Engineering Progress Symposium Series, Vo1. 63, No. 80,1967 , pages $156-162$.

2. L. E. Bruns, "Plutonium-Uranium Processing in the Plutonium Reclamation Facility by Coextraction-Partitioning," ARH-1343, Atlantic Richfield Hanford Company, Richland, Washington, September 25, 1969.

3. W. F. Bonner and G. L. Richardson, "Pilot Plant Demonstration of the Plutonium Reclamation Facility CC, CR, and CS Columns," BNWL-CC-2461, February 1970. 